\title{
Caspase-generated fragment of the Met receptor favors apoptosis via the intrinsic pathway independently of its tyrosine kinase activity
}

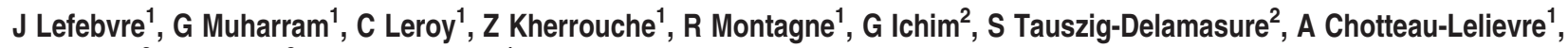 \\ C Brenner ${ }^{3}, \mathrm{P}$ Mehlen ${ }^{2}$ and D Tulasne ${ }^{*, 1}$
}

The receptor tyrosine kinase Met and its ligand, the hepatocyte growth factor, are essential to embryonic development, whereas the deregulation of Met signaling is associated with tumorigenesis. While ligand-activated Met promotes survival, caspasedependent generation of the p40 Met fragment leads to apoptosis induction - hallmark of the dependence receptor. Although the survival signaling pathways induced by Met are well described, the pro-apoptotic signaling pathways are unknown. We show that, although p40 Met contains the entire kinase domain, it accelerates apoptosis independently of kinase activity. In cell cultures undergoing apoptosis, the fragment shows a mitochondrial localization, required for p40 Met-induced cell death. Fulminant hepatic failure induced in mice leads to the generation of p40 Met localized also in the mitochondria, demonstrating caspase cleavage of Met in vivo. According to its localization, the fragment induces mitochondrial permeabilization, which is inhibited by Bak silencing and Bcl-xL overexpression. Moreover, Met silencing delays mitochondrial permeabilization induced by an apoptotic treatment. Thus, the Met-dependence receptor in addition to its well-known role in survival signaling mediated by its kinase activity, also participates in the intrinsic apoptosis pathway through the generation of p40 Met - a caspase-dependent fragment of Met implicated in the mitochondrial permeabilization process.

Cell Death and Disease (2013) 4, e871; doi:10.1038/cddis.2013.377; published online 17 October 2013

Subject Category: Cancer

Dependence receptors are bifunctional receptors that are able to mediate both efficient cell survival after ligand binding and apoptotic cell death in the absence of the ligand. To date, $>15$ dependence receptors have been identified, belonging to several membrane receptor families: single-pass type I receptors, receptor tyrosine kinases (RTK), integrins and multipass membrane proteins. For most dependence receptors, the cytoplasmic or membrane-anchored fragments generated by caspase cleavages are direct inducers of apoptosis. $^{1}$

The RTK Met is classified as a dependence receptor because it strongly induces cell survival in the presence of ligand and favors apoptosis when cleaved by caspase. ${ }^{2}$ Met, expressed predominantly at the surface of epithelial cells, is activated by its ligand - the hepatocyte growth factor/ scatter factor (HGF/SF). Ligand-activated Met stimulates proliferation, scattering, invasion and morphogenesis, and protects a number of cell types against apoptosis. ${ }^{3}$ The Met receptor and its ligand are essential to embryonic development, as mouse mutants affected in either ligand or receptor show defects in placenta, liver, muscle and neuron formation. $^{4-6}$ The size reduction of the liver in these mice results from massive apoptosis, highlighting the involvement of HGF/SF-Met signaling in hepatocyte survival. ${ }^{5}$

The PI3K-Akt and RAS-ERK signaling pathways have a central role in the anti-apoptotic responses induced by activated Met. $^{2}$ The apoptotic process is notably regulated by proteins of the $\mathrm{Bcl}-2$ family, whose action affects the intrinsic apoptosis pathway involving mitochondrial outer membrane permeabilization (MOMP). In many studies, HGF/SF-induced survival responses have been found to correlate with increased expression of the anti-apoptotic

\footnotetext{
${ }^{1}$ CNRS UMR 8161, Institut de Biologie de Lille - Institut Pasteur de Lille-IFR 142 - Université de Lille 1-Université de Lille 2, Lille, France; ${ }^{2}$ Apoptosis, Cancer and Development Laboratory-Equipe labellisée 'La Ligue', Centre de Cancérologie de Lyon, INSERM U1052-CNRS UMR5286, Université de Lyon, Centre Léon Bérard, Lyon, France and ${ }^{3}$ INSERM UMR S-769, Université Paris-Sud 11, Châtenay-Malabry, France

*Corresponding author: D Tulasne, CNRS UMR 8161, Institut de Biologie de Lille - Institut Pasteur de Lille, 1 Rue Pr Calmette, BP447, Lille 59021, France. Tel: + 333208712 57; Fax: + 3332087 11 11; E-mail: david.tulasne@ ibl.fr

Keywords: c-Met; receptor tyrosine kinase; hepatocyte growth factor/scatter factor; caspase; apoptosis; dependence receptor; mitochondrial permeabilization; Bcl-2 family

Abbreviation: ADD, addiction or dependence domains; Alk, Anaplastic lymphoma kinase; Bad, Bcl-2-associated death promoter protein; Bak, Bcl-2 Antagonist Killer; Bax, BCL-2-Associated X Protein; Bcl-xL, B-cell leukemia XL; Bcl-2, B-cell leukemia 2; BH3, Bcl-2 homology region 3; Caspase, Cysteine Aspartic Acid Specific Protease; CBL, Casitas b-lineage lymphoma; DCC, deleted in colorectal carcinoma; DISC, death-inducing signaling complex; EphA4, ephrin type-A receptor 4; ERK, extracellular-regulated kinase; FCS, fetal calf serum; GAPDH, glyceraldehyde-3-phosphate dehydrogenase; HGF/SF, hepatocyte growth factor/scatter factor; Mcl-1, myeloid cell leukemia-1; MDCK, Madin-Darby canine kidney epithelial cells; MOMP, mitochondrial outer membrane permeabilization; Nuc p62, Nucleoporin 62 kDa; PARP, poly ADP-ribose polymerase; PI3K, Phosphatidylinositide 3-kinase; ROCK1, Rho-associated kinase 1; RTK, receptor tyrosine kinase; SDS-PAGE, sodium dodecyl sulfate-polyacrylamide gel electrophoresis; SMS, SRC myristoylation site; TNF, tumor necrosis factor; TRKC, neurotrophic tyrosine kinase receptor type 3; UNC5, uncoordinated family member 5 ; zVAD-FMK, Z-Val-Ala-Asp (OMe)-fluoromethyl ketone

Received 21.3.13; revised 25.7.13; accepted 12.8.13; Edited by H-U Simon
} 
$\mathrm{Bcl}-\mathrm{xL}$ and $\mathrm{Bcl}-2$ proteins, which inhibit mitochondria-dependent apoptosis. ${ }^{7,8}$ Upon HGF/SF stimulation, furthermore, Akt phosphorylates the pro-apoptotic $\mathrm{BH} 3$-only protein $\mathrm{Bad}$, causing its inactivation and thereby preventing apoptosis. ${ }^{9}$

In addition to the well-known involvement of ligandactivated Met in cell survival, we previously demonstrated that the Met receptor can directly favor apoptosis. Under stress conditions, activated caspases can cleave Met within the C-terminal DNID $_{1374}$ motif and the juxtamembrane ESVD $_{1000}$ motif (mouse sequence), ${ }^{10,11}$ thus generating an intracellular $40-\mathrm{kDa}$ fragment containing the kinase domain. This p40 Met fragment can trigger apoptosis, and expression of a caspase-uncleavable Met causes resistance to apoptosis. In response to HGF/SF, induction of the survival signaling pathway and phosphorylation of Met near the juxtamembrane caspase site prevent the generation of p40 Met. $^{12}$

Although the survival signaling pathways induced by membrane receptors have been extensively studied, the relevant pro-apoptotic signaling pathways have been deciphered only recently. Caspase cleavages of DCC, Patched and UNC5 release fragments containing addiction or dependence domains (ADD) - that is, interacting domains promoting recruitment of pro-apoptotic factors. These recruitments lead to caspase activation - a mechanism reminiscent of the extrinsic apoptosis pathway. ${ }^{13}$

The mechanisms by which tyrosine-kinase-family dependence receptors promote apoptosis are unknown. We show here that $\mathrm{p} 40$ Met favors apoptosis independently of its kinase activity but triggers mitochondrial permeabilization. Thus, unlike previously described dependence receptors, Met amplifies apoptosis via the intrinsic pathway.

\section{Results}

Expression of p40 Met amplifies epithelial cell apoptosis. We have previously shown that during apoptosis, Met is cleaved by caspases giving rise to a $40-\mathrm{kDa}$ fragment ${ }^{10,11}$ (Figure 1a). For specific detection of p40 Met generation, we developed an antibody against the neo-epitope created by juxtamembrane cleavage. MCF-10A human mammary epithelial cells were treated for an increasing period of time with the apoptosis inducer staurosporin, and Met expression was evaluated with an antibody against its kinase domain or with the anti-p40 Met antibody. Whereas anti-Met kinase recognized both full-length Met and p40 Met, the anti-p40 Met detected only a $40-\mathrm{kDa}$ band during apoptosis (Figure 1b). This 40-kDa band was indeed the Met fragment, as a Met-targeting siRNA abolished its detection (Figure 1c). The p40 Met fragment appeared $2 \mathrm{~h}$ after staurosporin addition, simultaneously with the cleaved PARP, indicating that p40 Met generation occurs early in the apoptotic process.

We previously showed that p40 Met transient transfection induces caspase- 3 activation in about $15 \%$ of the transfected cells. ${ }^{11}$ To further evaluate the involvement of p40 Met expression, we generated Tet-on-inducible clones of MDCK normal canine kidney epithelial cells expressing the mouse Met fragment. Characterization of these inducible clones is shown in Supplementary Figure S1. For the clone a, we showed efficient detection of p40 Met with an anti-mouse Met antibody that does not detect the endogenous Met (Supplementary Figures S1A). Doxycycline was found to induce p40 Met expression in a dose-dependent manner with highest expression $12 \mathrm{~h}$ after induction (Supplementary Figures S1B and C). As shown in Figure 2a, when apoptosis was induced with TNF- $\alpha$ /cycloheximide, p40 Met expression was found to accelerate cell death. Indeed, after $4 \mathrm{~h}$ of TNF$\mathrm{CHX}$ stimulation, the relative caspase activity was twice as high in p40 Met-expressing cells as in control cells, whereas no caspase activity increase was observed in the absence of apoptosis induction (Figure 2b). This tallies with the level of cell death, as evaluated by trypan blue staining (Figure 2c). Acceleration of apoptosis was also observed by evaluation PARP and caspase-3 cleavages after stimulation with TNF$\mathrm{CHX}$ (Figure 2d). By contrast, inducible expression of $\mathrm{p} 40 \mathrm{Met}$ did not induce caspase activation on its own. Increase in PARP and caspase-3 cleavages were also observed after treatment with another apoptosis inducer anisomycin (Supplementary Figure S2A) and in a second p40 Metexpressing clone (clone b) (Supplementary Figure S2B). By contrast, wild-type MDCK cells (Supplementary Figure S2C) and Tet-on inducible MDCK cells expressing a kinase-dead p40 Met (p40 Met K1108A mutated at lysine 1108) (Supplementary Figure S2D) displayed no increase. In later time points of anisomycin treatment (10 and $12 \mathrm{~h}$ ), inducible p40 Met still increased cell death measured with trypan blue staining, with higher level of cell death as expected. However, at the end point of the time course $(16 \mathrm{~h})$, this increase is attenuated, suggesting that cell death reached its maximal level (Supplementary Figure S2E). It is noteworthy that in transiently transfected cells, p40 Met can induce apoptosis on its own. To check whether initial stress induced by transfection can reveal p40 Met pro-apoptotic function, we transfected the p40 Met Tet-on inducible cells with empty vector and induced fragment expression. We show that doxycycline treatment or transient transfection alone increased weakly or did not increase apoptosis monitored with annexin V staining. By contrast, transfected cells treated with doxycycline displayed significant increase in annexin V staining (Supplementary Figure S3), indicating that transfection-induced stress induced p40 Met-dependent apoptosis. Thus, the p40 Met fragment generated by caspase cleavage can accelerate apoptotic cell death when overexpressed.

The p40 Met fragment is not an active kinase. We have previously shown that the overexpression of p40 Met in transiently transfected cells can lead to its tyrosine phosphorylation. Furthermore, mutation of lysine 1108 involved in ATP binding abolished the apoptotic effects of p40 Met in both transiently transfected cells and the inducible model. We thus hypothesized that the p40 Met apoptotic effects might depend on its kinase activity. ${ }^{10}$ Therefore, we first determined its phosphorylation status, using antibodies against the phosphorylated tyrosines. In contrast to transient transfection experiments where p40 Met was phosphorylated, we failed to detect any phosphorylation of the fragment in extracts of whole cells undergoing apoptosis or even in fragment-enriched immunoprecipitates with the anti-p40 Met antibody (Figure 3a). We obtained similar results in a time course experiment (Supplementary Figure S4). In p40 


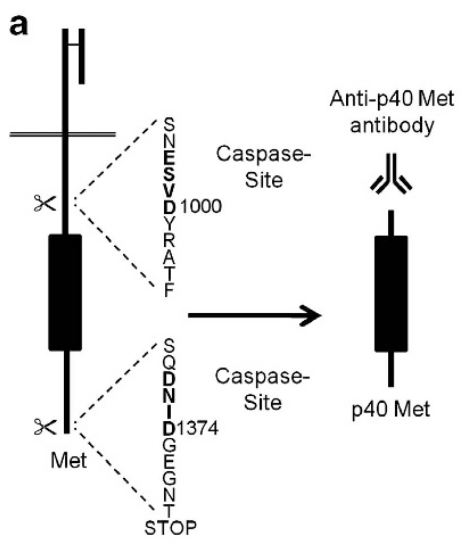

b
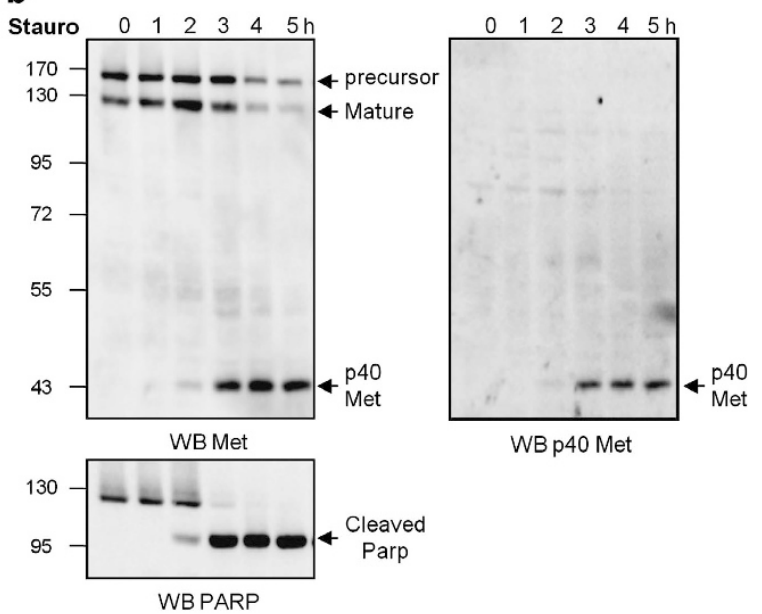

WB p40 Met
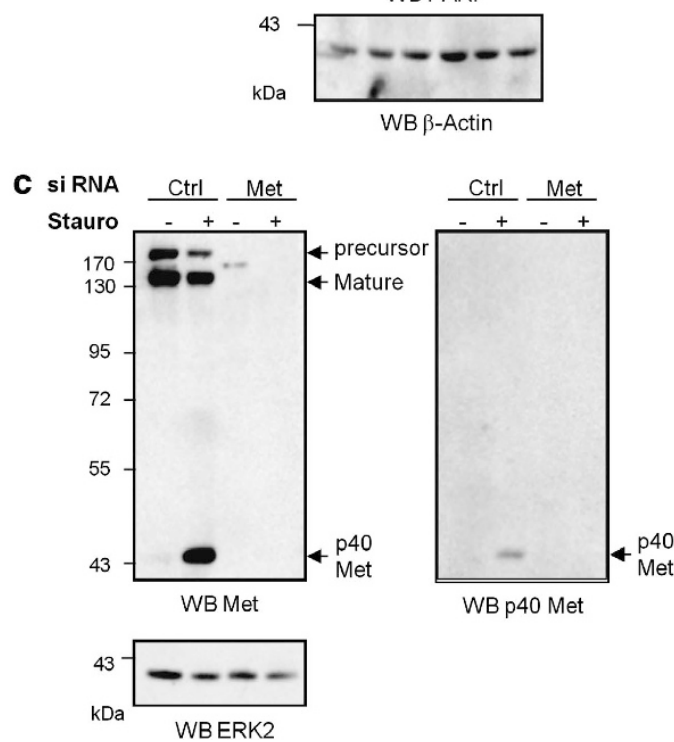

Figure 1 Specific detection of p40 Met during apoptosis. (a) Schematic representation of p40 Met generated by caspase cleavage of the full-length Met receptor during apoptosis. The neo-epitope produced by caspase cleavage of Met can be detected with a custom-made antibody. (b) MCF-10A epithelial cells were serum-starved overnight and treated for the indicated times with staurosporin (Stauro; $1 \mu \mathrm{M}$ ). (c) MCF-10A were transfected for $24 \mathrm{~h}$ with a control siRNA (lanes 1 and 2) or a pool of three siRNAs targeting Met, starved overnight and treated for $4 \mathrm{~h}$ with staurosporin. (b, c) For each condition, the same amount of proteins was resolved using $10 \%$ SDS-PAGE and analyzed using western blotting with antibodies against the kinase domain of Met, against p40 Met, or against PARP. To assess loading an anti- $\beta$-actin or an anti-ERK2 antibody was used

Met Tet-on inducible MDCK, likewise, we observed neither p40 Met phosphorylation nor kinase activity (Figure 3b). By contrast, the TPR-Met oncogene, a constitutively dimerized form of Met, displayed proper phosphorylation and kinase activity, whereas its kinase-dead version did not. Hence, the p40 Met generated during apoptosis is not a constitutively active kinase.

To test whether the action of $\mathrm{p} 40$ Met depends on its kinase activity, we determined the effects of ATP mimetics targeting selectively the Met kinase. Met inhibitor PHA-665752 failed to inhibit the apoptosis induced by ectopically expressed p40 Met, as evaluated by caspase-3 cleavage (Figure $3 c$ ). By contrast, such inhibitor prevented the HGF/SF-induced survival, as evaluated by Met and PARP cleavage (Supplementary Figure S5). In transformed cell lines displaying constitutive Met activation, inhibition of its expression or kinase activity can lead to apoptosis. ${ }^{14,15}$ We checked, in lung cancer cell lines EBC-1 displaying Met gene amplification, whether the induction of cell death with Met inhibitor can induce p40 Met generation. Indeed, the treatment of EBC-1 with PHA-665752 was sufficient to induce caspase- 3 activation accompanied with decrease in Met and generation of p40 Met fragment (Figure 3d). Taken together, our results show that, although the survival response induced by ligand-activated Met requires kinase activity, apoptosis enhancement by $\mathrm{p} 40$ Met does not.

The subcellular localization of p40 Met governs its pro-apoptotic action. To see how the localization of p40 Met might affect its pro-apoptotic action, we fused the 15AA of the SRC myristoylation site, responsible for its membrane anchorage, with p40 Met (SMS-p40 Met). Immunofluorescence staining revealed both cytoplasmic and nuclear p40 Met localization, whereas SMS-p40 Met was detected 
a MDCK Tet-on p40 Met clone a

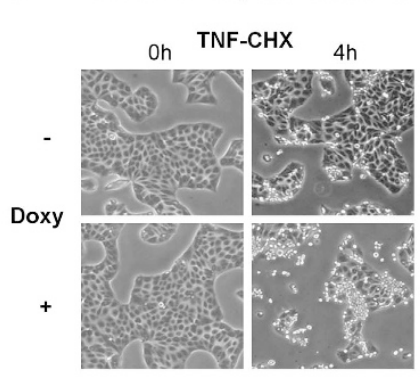

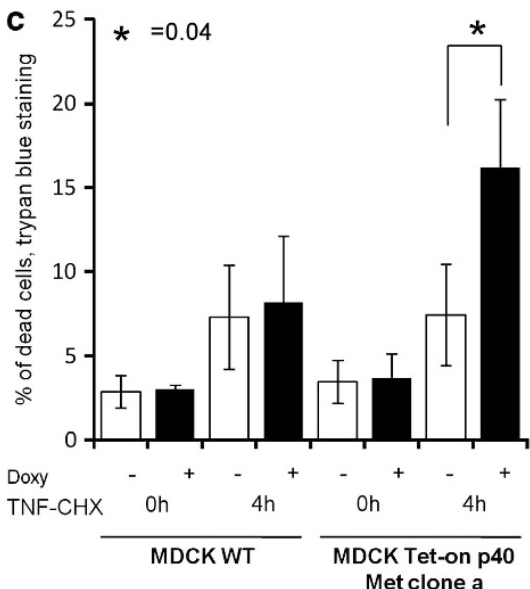

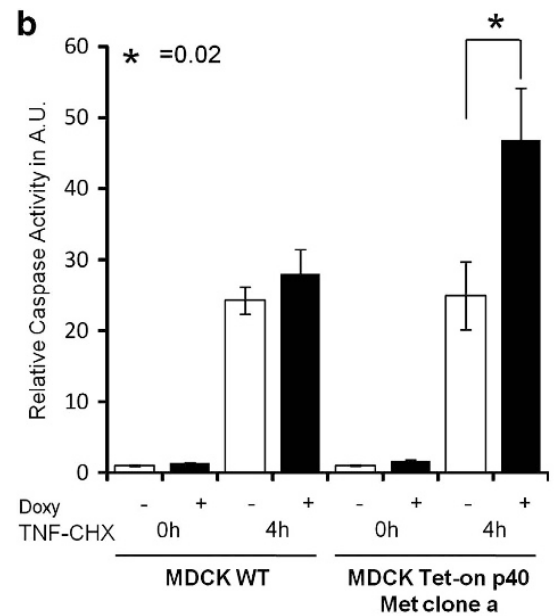

d

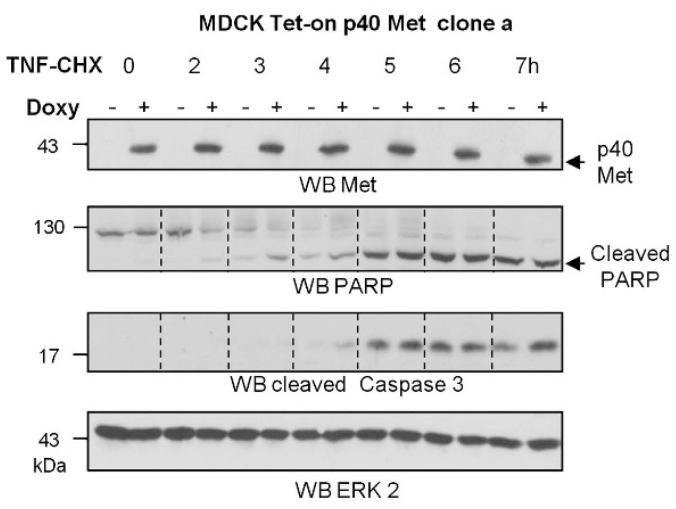

Figure 2 Consequence of p40 Met expression during the apoptotic response. (a-d) p40 Met Tet-on-inducible MDCK epithelial cells (clone a) and wild-type MDCK cells were starved, stimulated or not overnight (16 h) with $200 \mathrm{ng} / \mathrm{ml}$ doxycycline (Doxy) and treated for $4 \mathrm{~h}$ with $30 \mathrm{ng} / \mathrm{ml} \mathrm{TNF} \alpha$ and $10 \mu \mathrm{g} / \mathrm{ml}$ cycloheximide (CHX). (a) Pictures of Tet-On p40 Met MDCK epithelial cells (clone a). (b) Relative caspase activity was determined from the same amount of proteins $(n=3$; \pm S.D.; Student's test * 0.02$)$. (c) Cells were stained with trypan blue and the percentage of dead cells was determined $(n=3, \pm$ S.D.; Student's test * 0.04$)$. (d) Proteins were resolved using $12 \%$ SDS-PAGE and analyzed using western blotting with an anti-mouse Met antibody, an anti-PARP antibody, an anti-cleaved caspase-3 antibody and an anti-ERK2 antibody to assess loading

mainly at the plasma membrane (Figure 4a). Cell death, evaluated by cleaved caspase-3 staining in MDCK cells, appeared drastically reduced in SMS-p40 Met (Figure 4b). p40 Met and SMS-p40 Met have been detected using western blot at the expected size (Figure 4c). Thus, restoring the membrane localization of the Met kinase domain inhibits its pro-apoptotic action.

Mitochondrial localization of p40 Met. In subcellular fractionation experiments, p40 Met generated in staurosporin-treated MCF-10A cells was found in both the nuclear and mitochondrial fractions (Figure 5a). The effectiveness of purification was attested by the enrichment of Cox IV in the mitochondrial, Nuc p62 in nuclear and GAPDH in cytoplasmic fractions, respectively.

To assess the presence of p40 Met fragment in vivo, we examined its generation in the mouse treated with anti-Fas antibody (Jo2), known to induce massive hepatic apoptosis. ${ }^{16}$ Liver mitochondria were purified on percoll gradient and analyzed using western blotting (Figure 5b). The effectiveness of purification was attested by the presence Cox IV in the isolated mitochondria. Monitoring of caspase-3 activation in whole-liver extract confirmed the apoptosis-inducing action of Jo2. Full-length Met was present in the whole-liver extract, where its level decreased upon Jo2 treatment; however, it was never detected in the purified mitochondria. By contrast, a 40-kDa band was detected with the anti-Met antibody both in whole-liver extracts and purified mitochondria under apoptotic conditions. Detection of a similar 40-kDa band with the antip40 Met antibody confirms that it corresponds to the proapoptotic fragment. A fragment of similar size was observed in apoptotic MCF-10A (Figure 5b). Thus, p40 Met is generated in vivo in the apoptotic mouse liver and localizes predominantly to the mitochondria.

Mitochondrial localization of p40 Met was further confirmed with immunofluorescence detection. P40 Met WT (Figure 5d) and p40 Met K1108A (Supplementary Figure S6) displayed punctuated intracytoplasmic staining, the latter colocalizing partially with elongated shape of the mitochondria in MCF-10A cells. In order to define region involved in mitochondrial localization, we performed an N-terminal deletion of p40 Met until the 11180 (Figure 5c). Interestingly, this fragment 

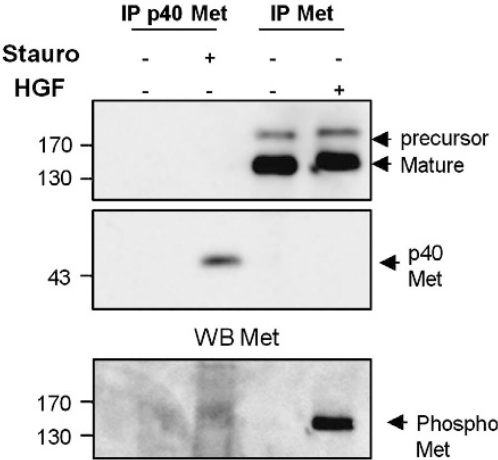
Met

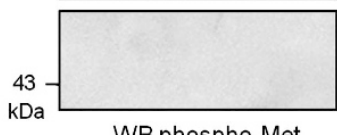

WB phospho-Met

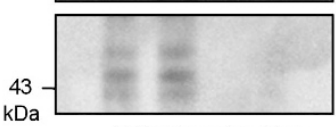

WB phospho-Met

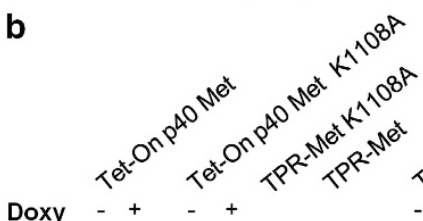

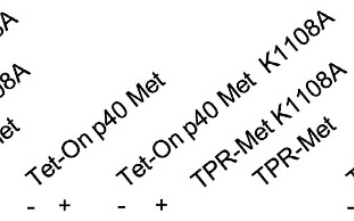

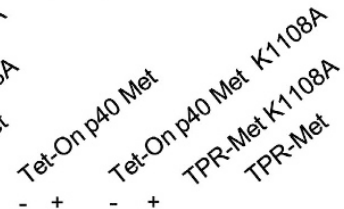

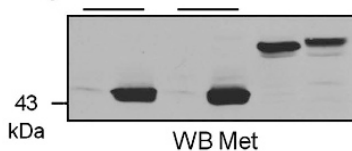

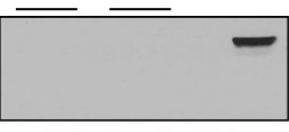

WB phospho-Met

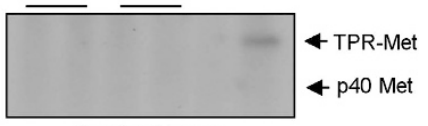

In vitro kinase

assay

d EBC-1 Cells

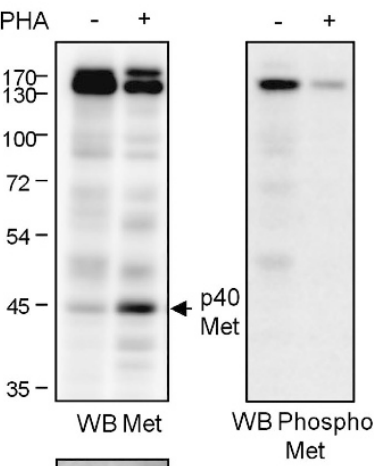

C

MDCK Cells

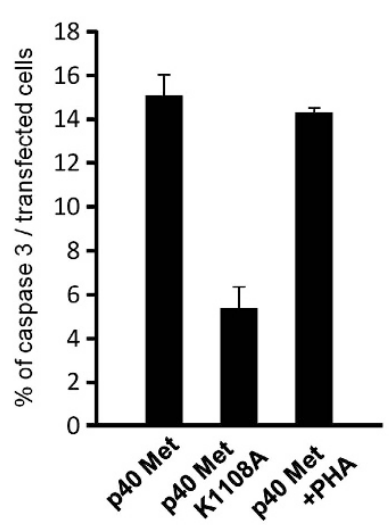

Figure 3 p40 Met phosphorylation and kinase activity. (a) MCF-10A epithelial cells were starved overnight and treated $4 \mathrm{~h}$ with $1 \mu \mathrm{M}$ staurosporin (Stauro) or 15 min with $30 \mathrm{ng} / \mathrm{ml} \mathrm{HGF/SF}$. Proteins were immunoprecipitated with antibody against the kinase domain of Met or against p40 Met and analyzed using western blotting with antibody against the kinase domain of Met or against the phosphorylated tyrosine residues of the Met kinase domain. (b) MDCK epithelial cells were transfected with a vector expressing the fusion protein TPR-Met or kinase-dead TPR-Met (mutation K1108A). WT or kinase-dead (K1108A) p40 Met Tet-on MDCK epithelial cells were starved and stimulated or not overnight with $200 \mathrm{ng} / \mathrm{ml}$ doxycycline. Proteins were immunoprecipitated with anti-mouse Met antibody or anti-human Met antibody. Immunoprecipitated proteins were resolved using $12 \%$ SDS-PAGE and analyzed using western blotting with an antibody against the kinase domain of Met or against the phosphorylated tyrosine residues of the Met kinase domain. (c) MDCK epithelial cells were transiently transfected with a vector expressing Flag-tagged wild-type or kinase-dead (K1108A) p40 Met and treated or not with $0.1 \mu \mathrm{M}$ PHA-665752. Twenty-four hours after transfection, the nuclei were stained with Hoechst, p40 Met was specifically labeled with an anti-flag antibody and an anti-cleaved caspase-3 antibody was used to detect apoptotic cells. The percentage of caspase-3-positive cells among the Met-expressing cells was determined. At least 200 cells were counted per well $(n=3 ; \pm$ S.D.). (d) Lung cancer cell line EBC-1 was treated $24 \mathrm{~h}$ with $0.1 \mu \mathrm{M}$ PHA-665752. Proteins were resolved using $10 \%$ SDS-PAGE and analyzed using western blotting with an antibody against the kinase domain of Met, an antibody against the phosphorylated tyrosine residues of the Met kinase domain, an anti-cleaved caspase-3 antibody and an anti-GAPDH antibody to assess loading 
a

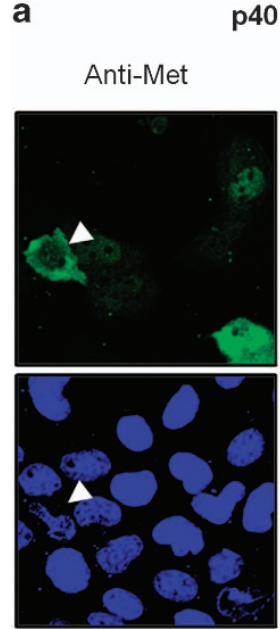

Hoechst p40 Met

Anti-cleaved caspase 3
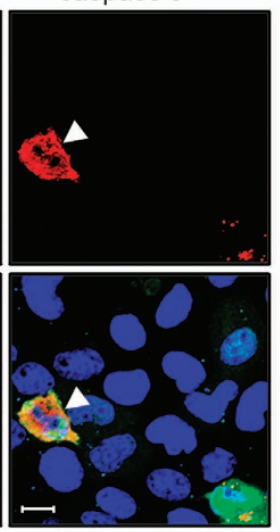

Merge

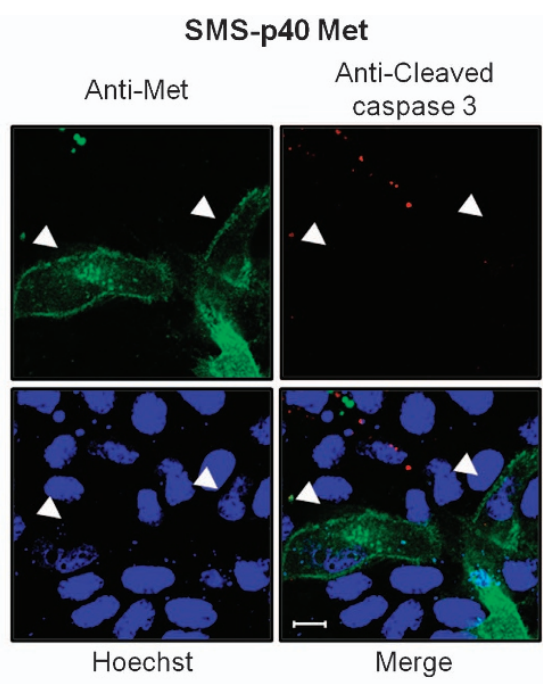

C
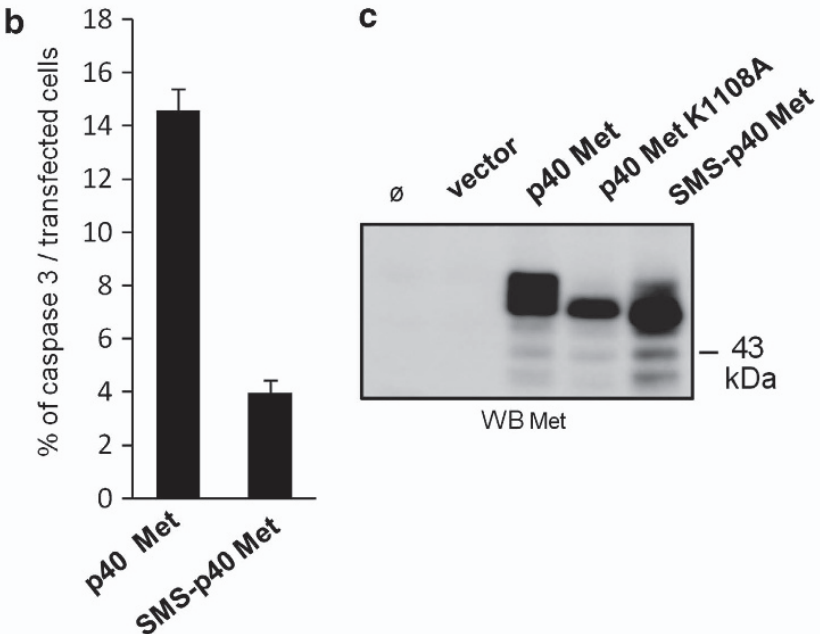

Figure 4 Effect of p40 Met localization on its apoptotic action. (a) MDCK epithelial cells were transfected with a vector expressing Flag-tagged wild-type p40 Met (p40 Met) or p40 Met fused to the Src myristoylation site (SMS-p40 Met). Twenty-four hours after transfection, the nuclei were stained with Hoechst (blue staining) and immunofluorescence staining was performed with an anti-mouse Met antibody (green staining) and an anti-cleaved caspase-3 antibody (red staining). Cells were observed using fluorescence microscopy. White arrows indicate representative transfected cells expressing p40 Met. (b) The percentage of caspase-3-positive cells among the Met-expressing cells was determined. At least 200 cells were counted per well $(n=3 ; \pm$ S.D.). (c) HEK 293 cells were transfected or not with an empty vector or a vector expressing Flag-tagged wild-type p40 Met (p40 Met) or SMS-p40 Met. Cell extracts were resolved using 12\% SDS-PAGE and analyzed using western blotting with an anti-mouse Met antibody to assess expression from the transfected vector

displayed an exclusive mitochondrial localization accompanied with a mitochondrial fragmentation (Figure $5 \mathrm{~d}$ ), suggesting that the $\mathrm{C}$-terminal region could target p40 Met to the mitochondria, whereas the $\mathrm{N}$-terminal region could be involved in other subcellular localization. However, this construct did not induce cytochrome- $c$ release (data not shown). Quantification of colocalization using GFP transfection and cytochrome- $c$ staining as negative and positive control, respectively (Supplementary Figure S6), confirmed the partial localization of p40 Met with the mitochondria (Figure $5 \mathrm{e}$ ).

p40 Met induces mitochondrial permeabilization. As K1108A mutation abrogates both kinase activity and apoptosis induced by p40 Met, we searched to identify mutations disrupting apoptotic response without affecting the kinase activity. A p40 Met mutated on amino-acid L1110 and D1115 located near the K1108 (p40 Met LD) did not induce caspase-3 activation (Figure 6a) but still displayed tyrosine phosphorylation upon transient transfection (Figure 6b). As expected, caspase inhibitor inhibited p40 Met-induced caspase-3 activation. This demonstrates further that kinase activity is not involved in the p40 Met-induced apoptosis.

We next evaluated whether p40 Met expression induces mitochondrial permeabilization a crucial step of apoptosis. The fragment was found to induce cytochrome- $c$ release in about $15 \%$ of the MCF-10A-transfected cells (Figure $6 \mathrm{c}$ ), whereas permeabilization induced by $\mathrm{p} 40 \mathrm{Met}$ LD fell to $5 \%$. In p40 Met-transfected cells, treatment with zVAD did not prevent cytochrome- $c$ release or nuclear condensation but on the contrary increased these phenomena. This increase 
a

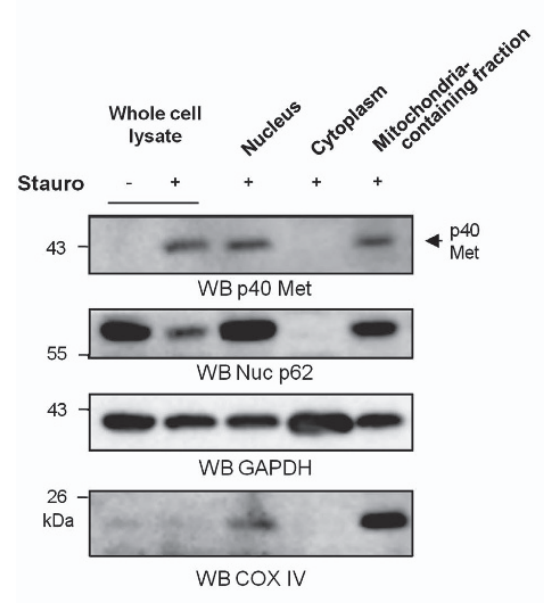

C
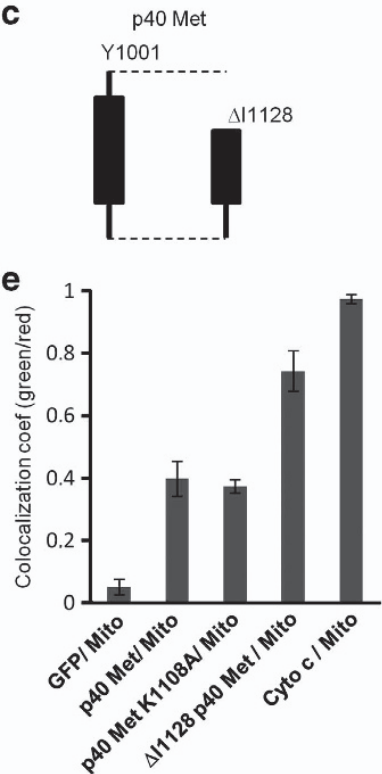

d b
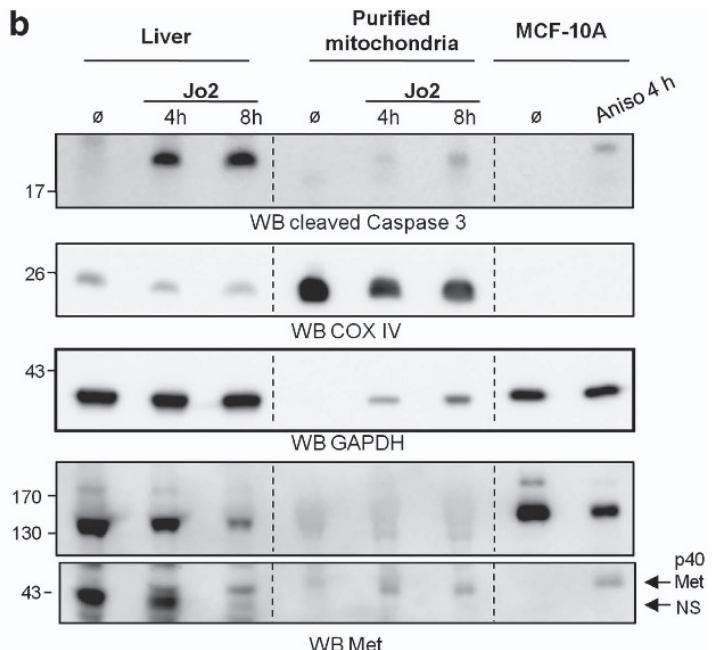

WB Met
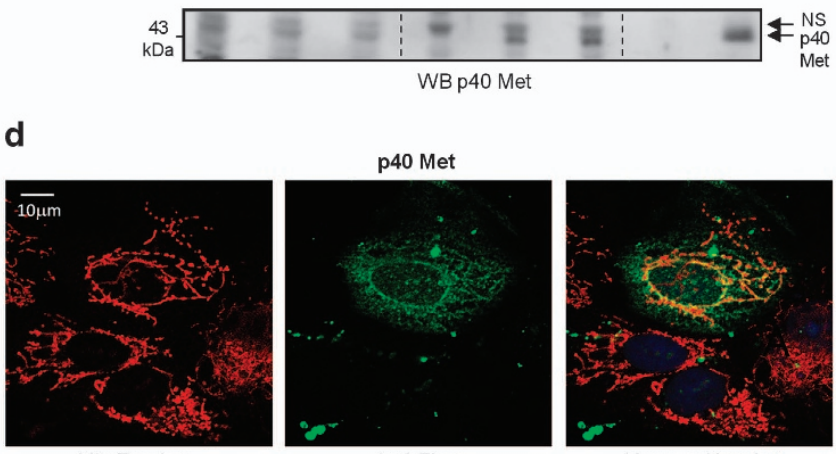

Anti-Flag

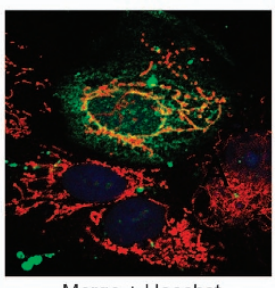

$\Delta \mathrm{I} 1128 \mathrm{p} 40 \mathrm{Met}$

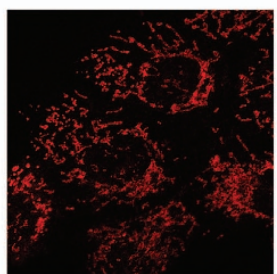

MitoTracker

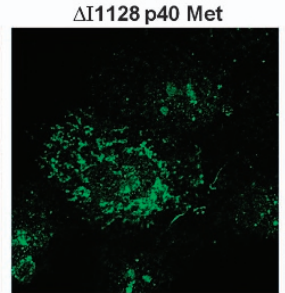

Anti-Flag

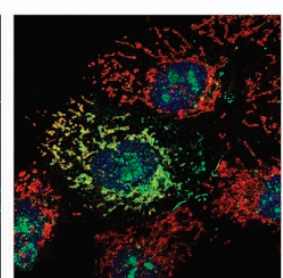

Merge + Hoechst

Figure 5 p40 Met localizes partially to the mitochondria. (a) MCF-10A epithelial cells were starved overnight and treated for $4 \mathrm{~h}$ with $1 \mu \mathrm{M}$ staurosporin (Stauro). After treatment, the cells were fractionated into a nuclear, a cytosolic and a mitochondrial fraction. The same amount of proteins from the whole-cell lysates and the different fractions was resolved using $12 \%$ SDS-PAGE and analyzed using western blotting with antibodies against p40 Met, the nuclear protein Nup 62, the cytosolic protein GAPDH or the inner mitochondrial membrane protein Cox IV. (b) Mice were injected with saline (ø) or Jo2 antibody at the indicated time. After treatment, their livers were removed and the mitochondria were isolated. The same amount of proteins from the liver and the purified mitochondria was resolved using 15 or $10 \%$ SDS-PAGE and analyzed using western blotting with antibodies against p40 Met, the kinase domain of Met, the cytosolic protein GAPDH or the inner mitochondrial membrane protein Cox IV. The same amount of MCF-10A whole-cell lysate, treated or not for $4 \mathrm{~h}$ with $1 \mu \mathrm{M}$ anisomycin, was used as a control for p40 Met detection. Arrows indicate p40 Met and a nonspecific band (NS). (c) Schematic representation of $\mathrm{p} 40 \mathrm{Met} \mathrm{N}$-terminally deleted versions. (d,e) MCF-10A epithelial cells were transfected with a vector expressing Flag-tagged wild-type p40 Met (p40 Met), kinase-dead p40 Met (p40 Met K1108A) or a Flag-tagged N-terminally deleted version until isoleucine 1128 ( $\Delta 11128$ p40 Met), as indicated. Twenty-four hours after transfection, the nuclei were stained with Hoechst (blue staining), the mitochondria were stained with MitoTracker (Red), and immunofluorescence staining was performed with an anti-Flag antibody (green staining). (d) The cells were observed using fluorescence confocal microscopy. (e) Weighted colocalization coefficients of GFP, p40 Met, p40 Met K1108A, $\Delta 11128$ p40 Met and Cytochrome-c staining (green) with Mitotracker staining (Red) were measured from the fluorescence confocal microscopy images ( $n=4$; \pm S.D.)

could be the consequence of an inhibition of the late stage of apoptosis controlled by caspases, which could increase the detection of mitochondrial release. In favor of this, the number of p40 Met-positive cells increased under the zVAD treatment (data not shown). The mitochondrial permeabilization induced by the fragment thus occurs independently of caspase activation. Similarly, p40 Met induced Bax activation monitored with the help of immunofluorescence using the antiBax antibody $6 \mathrm{~A} 7$, recognizing its active conformation. ${ }^{17} \mathrm{P} 40$ Met-induced Bax activation was also increased upon caspase inhibition (Figure 6d). This suggests that p40 Met may act at an early step of apoptosis to induce release from the mitochondria and that the caspase inhibitor might prevent later events in apoptosis. 
To assess the involvement of Bcl-2 regulators, we coexpressed the Met fragment with either the anti-apoptotic $\mathrm{Bcl}-2$ and $\mathrm{Bcl}-\mathrm{xL}$ or with siRNA targeting Bak and Bax. P40
Met-induced cytochrome- $c$ release was efficiently inhibited by $\mathrm{Bcl}-\mathrm{xL}$ co-expression, whereas Bcl-2 did not decrease it (Figures $7 \mathrm{a}$ and $b$ ). Efficient and selective silencing of Bak and

\section{b}
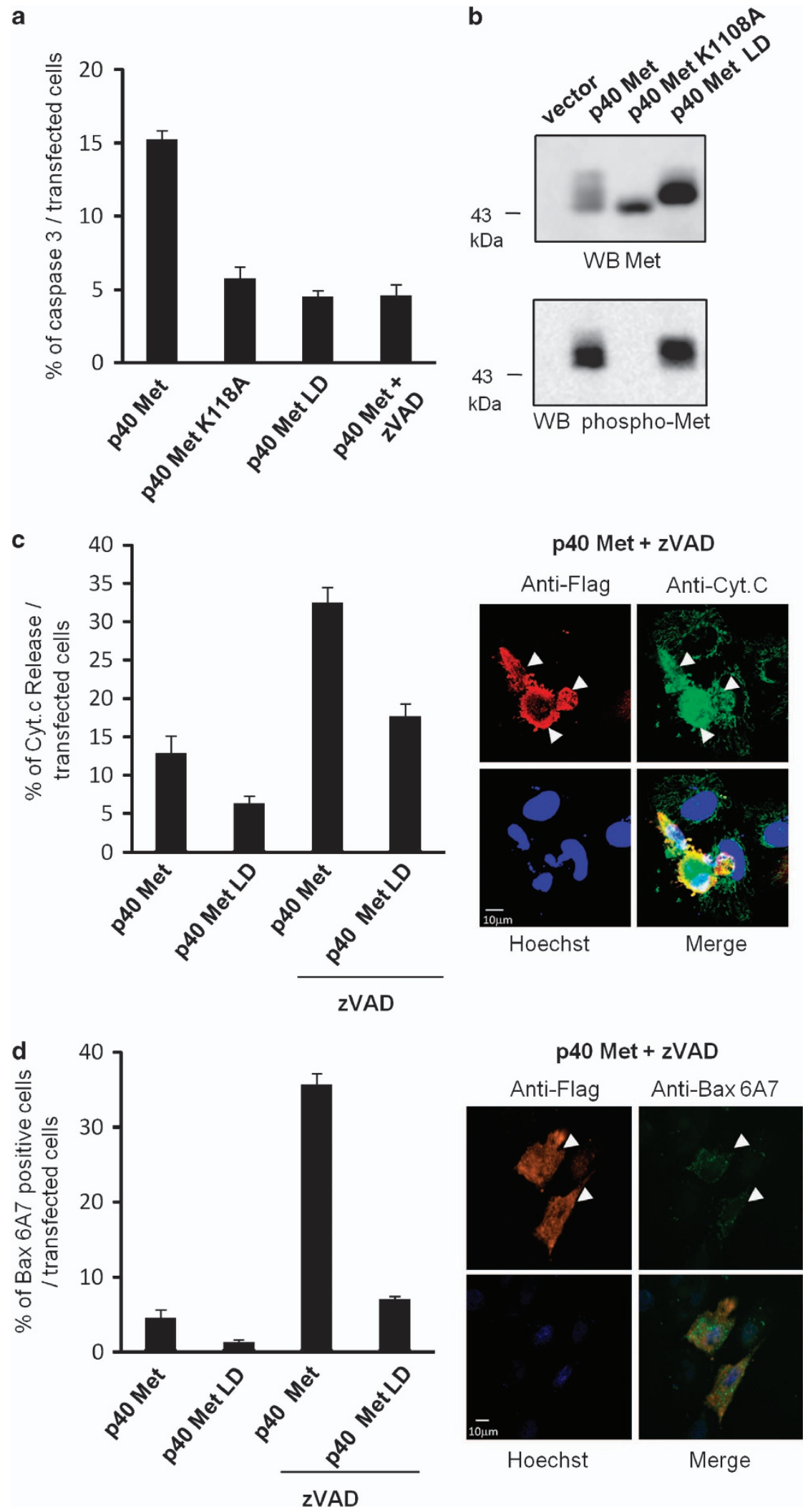

p40 Met + zVAD

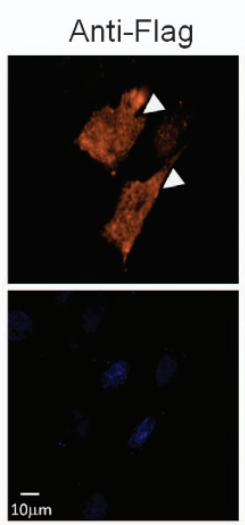

Hoechst
Anti-Bax 6A7

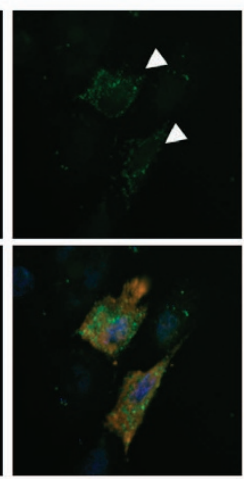

Merge 
Bax were assessed using quantitative RT-PCR and western blot (Figures 7c and d). P40 Met-induced cytochrome-c release was inhibited by the silencing of Bak (Figure 7e), notably after $72 \mathrm{~h}$ displaying optimal Bak silencing (Figure 7d), whereas silencing of Bax had no effect. This suggests that Met fragment-induced mitochondrial permeabilization is dependent on Bak pores negatively regulated by $\mathrm{Bcl}-\mathrm{xL}$.

The Met receptor is involved in both ligand-dependent survival and mitochondrial permeabilization. To evaluate the involvement of Met in the mitochondrial permeabilization, synthesis of the receptor was prevented with siRNA, and apoptosis was induced with staurosporin. Under control conditions, induction of apoptosis led to p40 Met generation (Figure $8 \mathrm{a}$ ), to cytochrome- $c$ release and to condensation and fragmentation of chromatin (pyknotic nucleus) in about half of the cells after a 3-h treatment (Figures $8 b-d$ ). In keeping with its survival response, HGF/SF prevented p40 Met generation (Figure 8a) and decreased cytochrome- $c$ release and the number of pyknotic nucleus (Figures $8 \mathrm{~b}$ and $\mathrm{c}$ ). The siRNAs against $c$-met inhibited the synthesis of both the full-length receptor and the p40 Met (Figure 8a). Under these conditions, cytochrome- $c$ release and the pyknotic nucleus were again reduced (Figures $8 b-d$ ). Hence, Met is indeed required for efficient mitochondrial release. As expected in the absence of its receptor, HGF/SF failed to prevent cytochrome- $c$ release upon Met silencing (Figure 8b). Thus, under stress and in agreement with the dependence paradigm, the Met receptor is required for ligand-triggered cell survival but also participates, in the absence of ligand and via p40 Met fragment, in mitochondrial permeabilization.

\section{Discussion}

Although p40 Met is generated by caspases, we detected its expression from $2 \mathrm{~h}$ after apoptosis induction, at a moment when caspases are not fully activated. The fragment was detected with a custom antibody recognizing the sequence immediately downstream from aspartic acid 1000, confirming that cleavage occurs at this site. The generation of $\mathrm{p} 40 \mathrm{Met}$ early in the apoptotic process and its pro-apoptotic action suggest that it contributes to apoptotic signaling. This hypothesis was confirmed with p40 Met Tet-on inducible cells, in which apoptosis is accelerated upon fragment expression. Altogether, our results suggest that p40 Met is an amplifier of apoptosis.
In caspase-targeted kinases, cleavage can lead to either activation or inactivation of kinase and this modulation has a direct impact on apoptosis. ${ }^{18}$ For instance, caspase cleavage of ROCK1 leads to kinase activation, phosphorylation of myosin light chains and subsequent membrane blebbing, which is the characteristic of apoptosis. ${ }^{19,20}$ By contrast, caspase cleavage abolishes activation of the Akt kinase, preventing the pro-survival responses. ${ }^{21}$ We initially demonstrated that the p40 Met includes the entire kinase domain and that the ATP-binding site mutation is sufficient to abolish its pro-apoptotic action. ${ }^{10}$ In addition, we observed that transiently transfected p40 Met displayed phosphorylation, suggesting that Met kinase could be involved in its pro-apoptotic function. However, we demonstrated here that the endogenous fragment generated during apoptosis and in Teton-inducible cells displays neither phosphorylation nor kinase activity. In addition, inhibitors of Met kinase do not affect p40 Met-induced cell death. Hence, Met caspase cleavages do not generate an active kinase. It is likely that p40 Met phosphorylation observed exclusively in transient transfections is the consequence of its massive expression. It is worth noticing that overexpression of the full-length Met through transient transfection ${ }^{22}$ or in cell lines harboring Met gene amplification ${ }^{14}$ leads to its constitutive phosphorylation.

Moreover, we have shown that p40 Met displays partial mitochondrial localization and is able to induce mitochondrial permeabilization. A pan-caspase inhibitor zVAD does not inhibit this permeabilization but, in the opposite way, increase it. Therefore, p40 Met controls MOMP independently of caspase activation, although its own generation requires caspase cleavages. Deletion of the $\mathrm{N}$-terminal region of $\mathrm{p} 40$ Met until 11128 increases its mitochondrial localization, suggesting that its $\mathrm{C}$-terminal region may be involved in its mitochondrial localization. Expression of $\mathrm{Bcl}-\mathrm{xL}$ decreases p40 Met-induced mitochondrial permeabilization, whereas $\mathrm{Bcl}-2$ is ineffective. In a complementary experiment, Bak silencing decreases permeabilization, whereas Bax silencing was ineffective. Thus, p40 Met-induced MOMP is dependent on Bak and is negatively regulated by $\mathrm{Bcl}-\mathrm{xL}$. Consistently, Bak interacts preferentially with $\mathrm{Bcl}-\mathrm{xL}$ and $\mathrm{Mcl}-1$, whereas Bax interacts preferentially with Bcl-2. ${ }^{23,24}$ Thus, Bak is displaced and it induces cell death when cytotoxic signals activate $\mathrm{BH} 3-$ only proteins that can engage both $\mathrm{Mcl}-1$ and Bcl-xL.

The survival response induced by ligand-stimulated Met notably involves increased expression of the anti-apoptotic $\mathrm{Bcl}-\mathrm{xL}$ and $\mathrm{Bcl}-2$ proteins, leading to the inhibition of mitochondria-dependent apoptosis. ${ }^{7,8}$ Under ligand stimulation,

Figure 6 Cytochrome-c release induced by p40 Met. (a) MCF-10A epithelial cells were transiently transfected with a vector expressing Flag-tagged wild-type p40 Met (p40 Met), kinase-dead p40 Met (p40 Met K1108A) or mutated on the amio acid L1110 and D1115 (p40 Met LD) and treated or not with $20 \mu$ M caspase inhibitor zVAD-FMK. Twenty-four hours after transfection, the nuclei were stained with Hoechst, and immunofluorescence staining was performed with an anti-mouse Met antibody and an anti-cleaved caspase-3 antibody. The percentage of activated caspase-3 among the Met-transfected cells was determined. At least 200 cells were counted per well $(n=3$; \pm S.D.). (b) HEK 293 cells were transfected or not with an empty vector or a vector expressing Flag-tagged wild-type p40 Met, p40 Met K1108A or p40 Met LD. Cell extracts were resolved using 12\% SDS-PAGE and analyzed using western blotting with an anti-mouse Met and anti-phospho Met antibodies. (c,d) MCF-10A epithelial cells were transiently transfected with a vector expressing Flag-tagged wild-type p40 Met or p40 Met LD and treated or not $20 \mu \mathrm{M}$ caspase inhibitor zVAD-FMK. Twenty-four hours after transfection, the nuclei were detected with Hoechst (blue staining) and immunofluorescence staining was performed with an anti-Flag antibody (red staining) and an anticytochrome-c (c) or an anti-Bax 6A7 antibody (d) (green staining). Cells were observed using fluorescence microscopy. The percentage of Met-transfected cells displaying cytochrome-c release was determined. At least 200 cells were counted per well $(n=3 ; \pm$ S.D.). Representative pictures of transfected cells displaying cytochrome-c release or Bax $6 \mathrm{~A} 7$ staining are shown. White arrows indicate transfected cells 

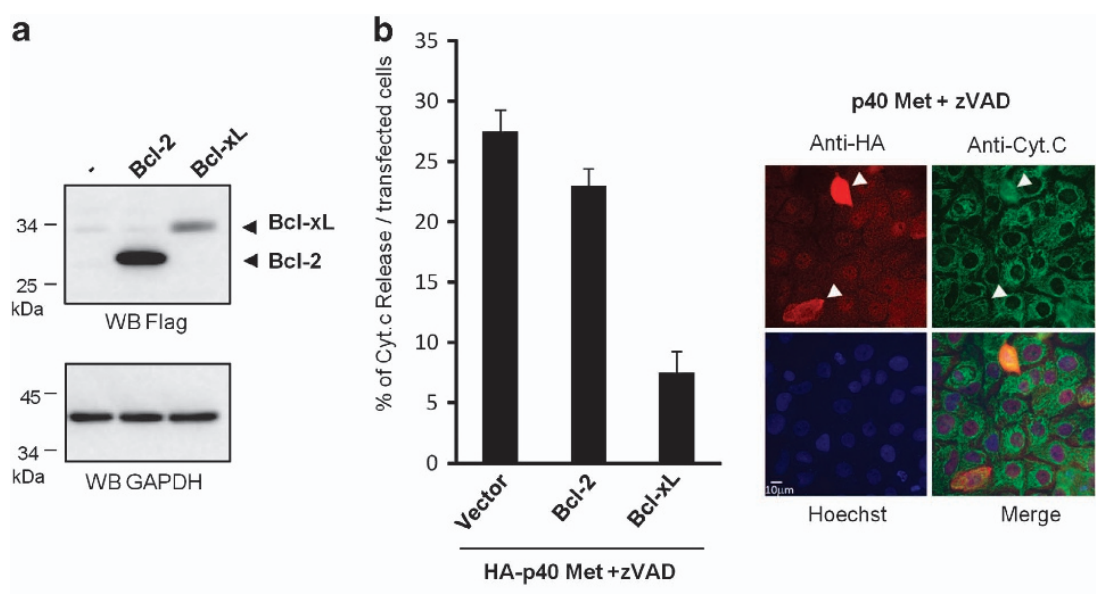

C

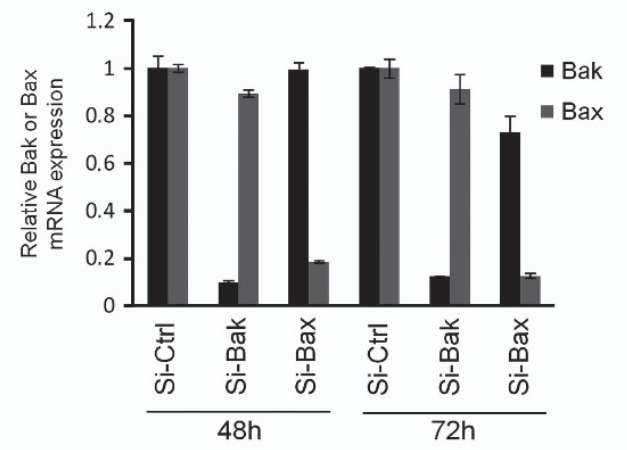

d

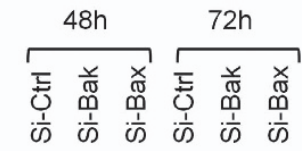

e
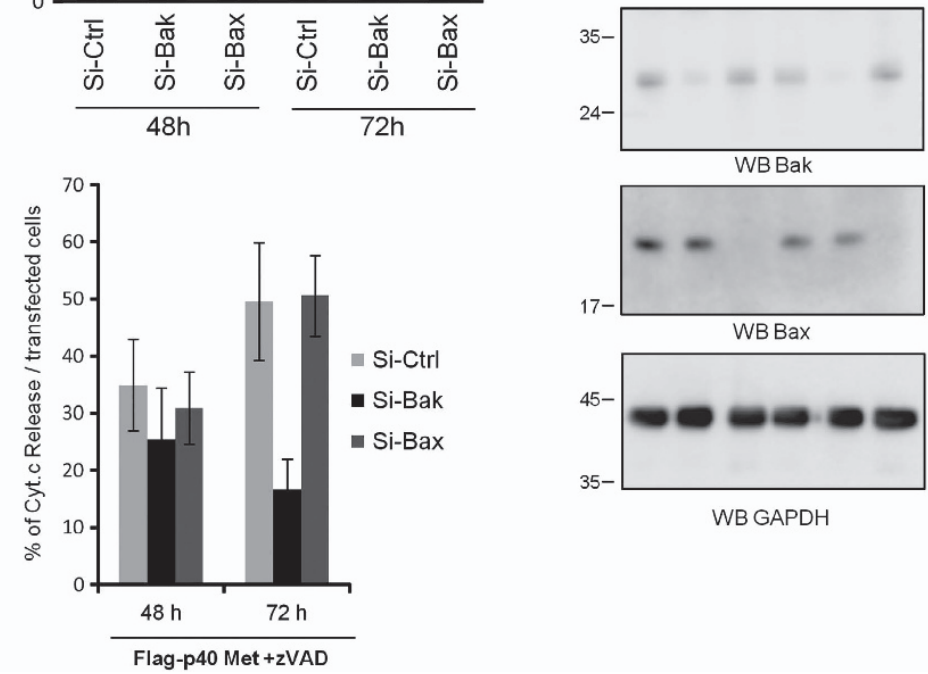

WBGAPDH

Figure 7 Effect of Bcl-2 or Bcl-xL expression and Bak or Bax silencing on p40 Met-induced mitochondrial permeabilization. (a, b) MCF-10A epithelial cells were transiently transfected with a vector expressing HA-tagged wild-type p40 Met and with vectors expressing Flag-tagged Bcl-2 or Bcl-xL and treated with $20 \mu \mathrm{M}$ caspase inhibitor zVADFMK. (a) Twenty-four hours after transfection, cells were lysed and extracts were resolved using 10\% SDS-PAGE and analyzed using western blotting with anti-Flag and antiGAPDH antibodies. (b) For immunofluorescence, the nuclei were detected with Hoechst, and immunofluorescence staining was performed with an anti-HA antibody and an anti-cytochrome-c antibody. Cells were observed using fluorescence microscopy. The percentage of p40 Met-transfected cells displaying cytochrome-c release was determined. At least 200 cells were counted per well $(n=3 ; \pm$ S.D.). Representative picture of transfected cells displaying or not cytochrome-c release is shown. White arrows indicate transfected cells. (c-e) MCF-10A epithelial cells were transfected with siRNA control or targeting Bak or Bax. The next day (48 h) or 2 days later (72 h), the cells were transfected by Flag-tagged wild-type p40 Met. Twenty-four hours after p40 Met transfection, the cells were lysed and extracts were analyzed using quantitative RT-PCR for expression of Bak and Bax mRNA ( $n=5 ; \pm$ S.D. in two independent experiments) (c) or using western blotting with an anti-Bak and an anti-Bax antibody. Similar extracts were then analyzed with an anti-GAPDH antibody (d). For immunofluorescence, the nuclei were detected with Hoechst, and immunofluorescence staining was performed with an anti-Flag antibody and an anti-cytochrome-c antibody. Cells were observed using fluorescence microscopy. The percentage of Met-transfected cells displaying cytochrome-c release was determined. At least 200 cells were counted per well $(n=3 ; \pm$ S.D.) (e)

we previously showed that tyrosine phosphorylation of the residue 1001 of the CBL-binding site prevents caspase cleavage at the aspartic acid $1000,{ }^{12}$ thus inhibiting p40 Met generation. In the absence of ligand and under stress, by contrast, p40 Met promotes mitochondria-dependent apoptosis involving Bak and is negatively regulated by $\mathrm{Bcl}-\mathrm{xL}$. Thus, the Met receptor can affect intrinsic apoptosis in opposite ways according to the cellular conditions, tipping the survival/ apoptosis balance one way or the other. These opposite responses were confirmed by silencing Met, inhibiting both survival induced by HGF/SF and the mitochondrial release in the absence of ligand. 
a

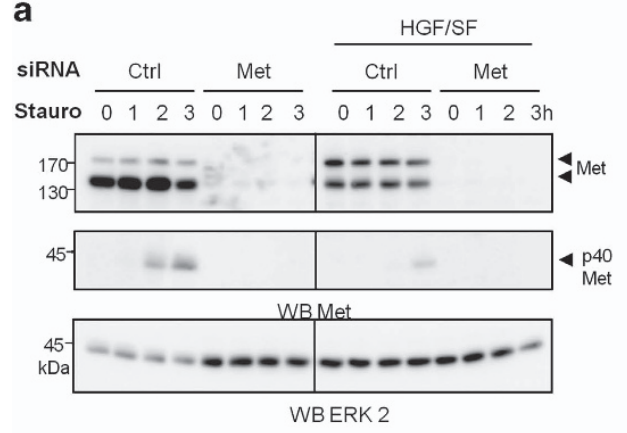

d

$\begin{array}{cc}\text { SiRNA } & \text { Ctrl } \\ \text { Stauro } & \text { Oh }\end{array}$

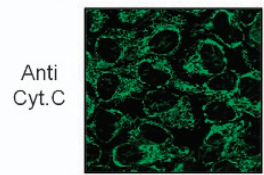

Hoechst 200

Merge
Met

Oh
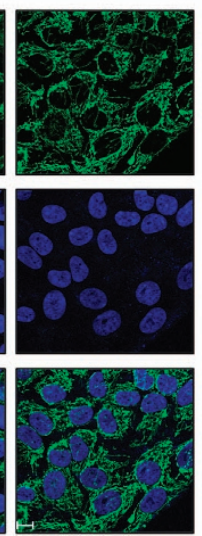
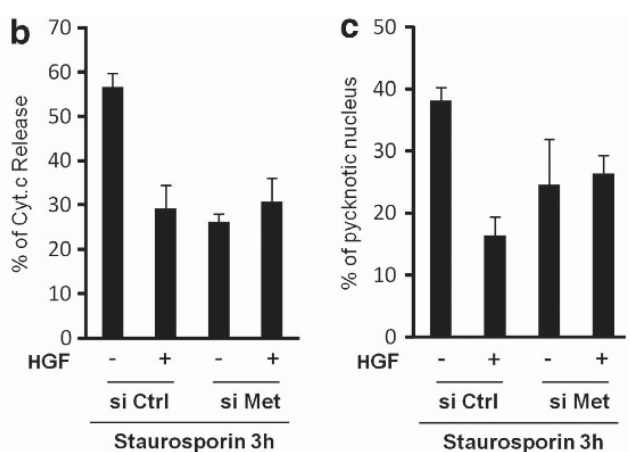

Met

$2 \mathrm{~h}$
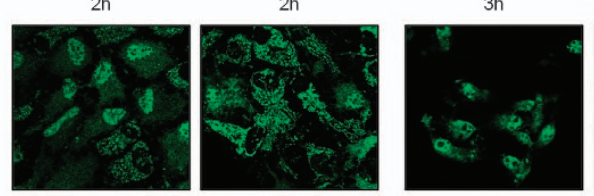

$3 \mathrm{~h}$
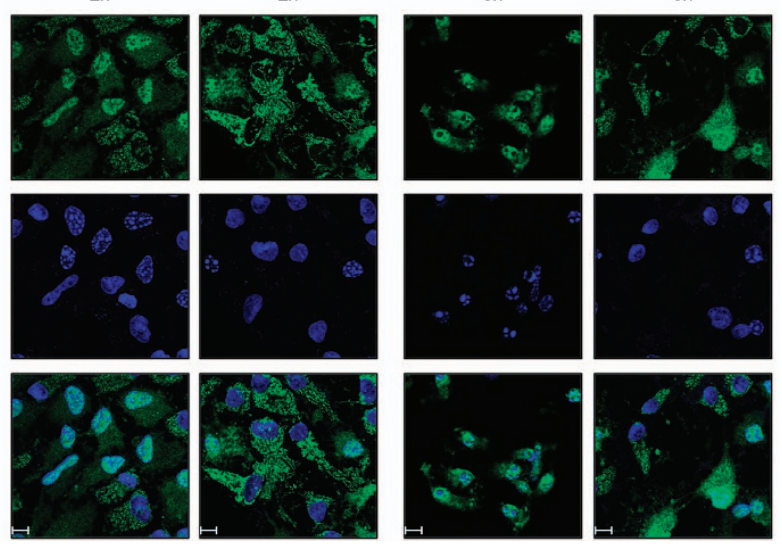

Figure 8 Consequence of Met silencing on mitochondrial release. (a-d) MCF-10A epithelial cells were transfected with a control siRNA or a pool of three Met-targeting siRNAs for $24 \mathrm{~h}$ and starved overnight. Then the cells were treated for $2 \mathrm{~h}$ with HGF/SF $(30 \mathrm{ng} / \mathrm{ml})$ before staurosporin $(1 \mu \mathrm{M})$ treatment at the indicated time. (a) Cells were lysed, proteins were resolved using 10\% SDS-PAGE and analyzed using western blotting with antibodies against the kinase domain of Met and against ERK2. (b-d) For each condition, the nuclei were stained with Hoechst (blue staining), and immunofluorescence was performed with an anti-cytochrome-c antibody (green staining). Cells were observed using fluorescence microscopy. (b,c) The percentage of cells displaying cytochrome-c release and condensed chromatin (pyknotic nucleus) were determined (200 cells were counted per well; $n=3 ; \pm$ S.D.)

We have previously shown that generation of the pro-apoptotic fragment $\mathrm{p} 40$ Met required initial cleavages by caspase-3. In addition, in contrast to other dependence receptors such as DCC and UNC5H, ectopic expression of full-length Met does not lead by its own to apoptotic cell death. ${ }^{11}$ Tet-on-inducible cells revealed now that the fragment is able to accelerate cell death only when cells are engaged in the apoptotic process. Therefore, the action of Met as dependence receptor seems conditioned by an original stress sufficient to initiate apoptosis.

The apoptotic responses induced by several dependence receptors have recently been elucidated. For instance, upon ligand withdrawal, DCC is cleaved by a first round of local caspase activation, which leads to the exposure of an addiction or dependence domain (ADD). The receptor then associates indirectly with caspase-9, leading to further caspase activation. ${ }^{25,26}$ In the case of Patched, ligand withdrawal initiates its caspase cleavage, allowing recruitments of DRAL, TUCAN and caspase-9. These mechanisms are reminiscent of those triggered by death receptors such as FAS which, by recruiting the death-inducing signaling complex (DISC), control caspase-8 activation. ${ }^{27}$ This has led to the view that Patched and DCC dependence receptors trigger extrinsic apoptosis. We demonstrate here that upon Met cleavage, the p40 Met promote mitochondrial permeabilization, which amplifies apoptotic cell death. The Met-dependence receptor thus triggers apoptosis via the intrinsic pathway. Interestingly, it is the membrane-anchored fragments of DCC and Patched that induce apoptosis, whereas the pro-apoptotic p40 Met fragment is no longer linked to the membrane and can localize to the mitochondria. This suggests that the subcellular localization of the ADD-containing fragment may determine the apoptotic pathway. For RTKs such as Ret and TRKC, the ADD domain is in the cytoplasmic fragment, whereas for Alk and EphA4, it remains anchored to the membrane. ${ }^{13}$ This suggests that these RTKs may cause dependence through distinct mechanisms.

In transformed cells, the survival/apoptosis balance is often deregulated in favor of survival. The Met receptor may contribute to this imbalance through its aberrant activation, leading to survival. ${ }^{3}$ Many strategies are developed to prevent Met activation, such as the use of ATP mimetics targeting Met kinase or silencing of Met expression. ${ }^{28}$ We show here that, in lung cancer cell lines EBC-1 exhibiting Met-addiction, treatment with Met kinase inhibitor was sufficient to induce caspase-3 activation accompanied with the generation of the p40 Met fragment. Interestingly, Met kinase inhibitors efficiently prevent Met-dependent survival without affecting 
p40 Met-induced apoptosis. By contrast, silencing of Met expression with siRNA inhibits both ligand-dependent survival and p40 Met-dependent mitochondrial release. Our findings thus reveal that Met kinase inhibitors offer the advantage of preserving the pro-apoptotic action of Met, which could further participate in causing the death of treated transformed cells.

\begin{abstract}
Materials and Methods
Cytokines, drugs and cell cultures. Human recombinant HGF/SF and TNF $\alpha$ were purchased from Peprotech (Rocky Hill, NJ, USA). The Met kinase inhibitors PHA-665752 and SU-11274 were purchased from Promega (Madison, WI, USA) and Biomol Research Laboratories (Philadelphia, PA, USA), respectively. Anisomycin and the caspase inhibitor zVAD-FMK were purchased from Calbiochem (San Diego, CA, USA). Staurosporin, doxycycline and cyclosporin A were purchased from Sigma (St Louis, MO, USA). Cycloheximide was purchased from ICN (Irvine, CA, USA).

HEK 293, Madin-Darby canine kidney (MDCK) epithelial cells and p40 Met Tet-on inducible MDCK epithelial cells were cultured in Dulbecco's Modified Eagle's Medium (DMEM) (Invitrogen, Carlsbad, CA, USA) supplemented with 10\% fetal bovine serum (FBS, Invitrogen) or fetal bovine serum tetracycline free (Clontech, Mountain View, CA, USA) and $1 \%$ antibiotics (penicillin $10000 \mathrm{U} / \mathrm{ml}$ - Streptomycin $10000 \mu \mathrm{g} / \mathrm{ml}$, Invitrogen). MCF-10A spontaneously immortalized human mammary epithelial cells were cultured in DMEM and HAM's F12 vol/vol (Invitrogen) supplemented with $5 \%$ horse serum (Invitrogen), $500 \mathrm{ng} / \mathrm{ml}$ hydrocortisone (Calbiochem), $20 \mathrm{ng} / \mathrm{ml}$ epidermal growth factor (Peprotech), $10 \mu \mathrm{g} / \mathrm{ml}$ insulin (Sigma), and $100 \mathrm{ng} / \mathrm{ml}$ cholera toxin (Calbiochem) and $1 \%$ antibiotics. Cells were cultured at $37^{\circ} \mathrm{C}$ in a water-saturated $5 \% \mathrm{CO}_{2}$ atmosphere. Non-small cell lung cancer cell line EBC-1 was cultured in EMEM (Invitrogen) supplemented with 10\% FBS and $1 \%$ antibiotics.
\end{abstract}

Antibodies. Mouse monoclonal antibody against the $\mathrm{C}$-terminal domain of mouse Met (B-2) and antibody against Bax (6A7), goat polyclonal antibody against the C-terminal domain of human actin (C-11), rabbit polyclonal against the C-terminal domain of human PARP-1 (H250), antibody against ERK2 (C14) and antibody against Bak (G23) were purchased from Santa Cruz Biotechnology (Santa Cruz, CA, USA). Mouse monoclonal antibody against the kinase domain of Met (3D4), Green-fluorescent Alexa fluor 488-conjugated anti-mouse $\lg G(\mathrm{H}+\mathrm{L})$ and red-fluorescent Alexa fluor 594-conjugated anti-rabbit $\lg G(\mathrm{H}+\mathrm{L})$ were purchased from Invitrogen. Mouse antibody against cytochrome-c oxidase subunit 4 (20E8) and nucleoporin p62 were purchased from Abcam (Cambridge, MA, USA). Rabbit polyclonal antibody against activated caspase-3 (Asp 275, no. 9661) and against the phosphorylated tyrosine (Y 1234/1235) of the Met kinase domain (no. 3126) were purchased from Cell Signaling Technology (Danvers, MA, USA). Rabbit polyclonal antibodies against the Flag and HA epitopes were purchased from Sigma. Custom polyclonal antibody against p40 Met was produced by Covalab (Villeurbanne, France). Briefly, rabbits were first injected twice with bridging peptide (NH2-NESVDYRATFPC-COOH, corresponding to the uncleaved sequence of Met) coupled to keyhole limpet hemocyanin without adjuvant. Secondly, rabbits were injected twice with neo-peptide NH2-YRATFPC-COOH, corresponding to the neo-epitope generated by caspase cleavage, ${ }^{10}$ coupled to ovalbumin with Freund's incomplete adjuvant. The antibodies were immunoaffinitypurified first by passage of the sera through a bridging peptide sepharose column and then by passage of the flow-through through the Met neo-peptide sepharose column. The J02 antibody (Purified NA/LE) against mouse CD95 (the Fas receptor) was purchased from BD Pharmingen (San Diego, CA, USA). Peroxidase-conjugated antibodies against rabbit and mouse IgGs were purchased from Jackson Immunoresearch Labs (West Grove, PA, USA).

Plasmid constructs. The pSTAR vectors encoding wild-type and K1108A p40 Met were constructed as follows. Mouse Met fragments (wild-type and K1108A) were amplified using PCR with the following primers $5^{\prime}$-CAGAATT CATGTACAGAGCTACTTTTCCAG-3' containing the ECORI restriction site and $5^{\prime}$-GTGGATCCTCAATCAATGTTGTCTTGGGATG-3' containing the BamHI restriction site. The PCR products were inserted into PSTAR $^{29}$ between the EcoRI and BamHI restriction sites.

The N-terminally deleted p40 Met 11128 was generated with mouse Met sequence amplified using PCR with the following forward primers: $5^{\prime}$-CTGACT GAGGGATCCATCATG- $3^{\prime}$ containing the BamHI restriction site and the reverse primer 5'-GGGCCCTCTAGACCCCTAGCCATC-3' containing an Xbal restriction site and inserted into pcDNA3 flag between the $B a m H I$ and $X$ bal restriction sites.

The pCMV plasmid constructs encoding HA-tagged wild-type and kinase-dead p40 Met were made as follows. Mouse Met fragments (wild-type and K1108A) were amplified using PCR with the following primers $5^{\prime}$-CCCGAATTCAATACAGAGC TACTTTTCCAGAA- $3^{\prime}$ containing an ECORI restriction site and $5^{\prime}$-GTACCTC GAGCCCCTCTCAATCAATGTTGTCTTGGG-3'. The PCR product was inserted into pCMV-Ha from Clontech.

The p40 Met fragment mutated at L1110E and D1115E was created with the QuickChange site-directed mutagenesis system of Stratagene, using pcDNA3 Flag p40 Met WT as a template and the following primers:

$5^{\prime}$-GTGCTGTGAAATCCGAGAATAGAATCACAG-3' and $5^{\prime}$-CTGTGATTCTA TTCTCGGATTTGACAGCAC-3' or $5^{\prime}$-GAATAGAATCACAGAGATAGAAGAGGT CTC- $3^{\prime}$ and $5^{\prime}$-GAGACCTCTTCTATCTCTGTGATTCTATTC- $3^{\prime}$. The amplified sequences were subcloned into pcDNA3 Flag between the BamHI and Xhol restriction sites and the presence of the mutation was confirmed using sequencing.

SMS-p40 Met was constructed as follows. The mouse Met fragment was amplified using PCR with the following primers: $5^{\prime}$-CTGGCGGCCGCCTACA GAGCTACTTTTCCAGAAGACCAG-3' containing a Notl restriction site and 5'-TACCTCTAGATCAATCAATGTTGTCTTGGGATGGCAAC- $3^{\prime}$ containing an $X$ bal restriction site. The PCR product was subcloned into pcDNA3-SMS between the Notl and Xbal restriction sites. Plasmid pcDNA3-SMS was constructed as follows. A vector containing v-src was amplified using PCR with the following primers $5^{\prime}$-GAATTAATTGCGGCCGCATTGAAAGCGTTAAC-3' containing a Notl restriction site and $5^{\prime}$ GACGTGAAGCTTACCACCATGGGGAG-3' containing a Hindlll restriction site. The PCR product was subcloned into an empty pcDNA3 vector between the HindIII and Nott restriction sites. Flag-tagged Bcl-2 and BcL-XL expressing vectors were generously provided by Gabriel Nunez (University of Michigan Medical School, Ann Arbor, MI, USA).

Transfections. Transfections of HEK 293 and MDCK cells with polyethyleneamine (PEI) Exgen 500 (Euromedex) and Lipofectamine (Invitrogen) reagents were performed as previously described. ${ }^{11}$ MCF-10A cells were plated on glass coverslips in 12-well plates (100000 per well). The next day, the cells were transfected with Jet Prime (Polyplus Transfection, Illkirch, France; $0.75 \mu \mathrm{g}$ DNA $/ 1.2 \mu \mathrm{l}$ Jet Prime reagent $/ 75 \mu \mathrm{l}$ Jet Prime buffer in $2 \mathrm{ml}$ complete medium). After $4 \mathrm{~h}$, the transfection medium was replaced by complete medium.

RNA interference. For Met silencing, MCF-10A cells were harvested. A total of 200000 cells were incubated with $3 \mu$ l Lipofectamine 2000 (Invitrogen) mixed with $3 \mathrm{~nm}$ of a pool of three stealth siRNAs (Invitrogen) targeting Met (5'-CCAUUUCAACUGAGUUUGCUGUUAA-3', 5'-UCCAGAAGAUCAGUUUCCU AAUUCA-3', 5'CCGAGGGAAUCAUCAUGAAAGAUUU-3'). The cells were then plated in a six-well plate in complete medium. For Bak and Bax silencing, MCF-10A were plated on glass coverslips in 12-well plates (100000per well). The next day, cells were incubated with $4 \mu$ l Jet Prime mixed with $40 \mathrm{~nm}$ siRNA targeting Bak (5'-GAGAAUGCCUAUGAGUACUUCACCA-3') or Bax (5'-CCCAC CAGCUCUGAGCAGAUCAUGA-3'). The next day or 2 days later, the cells were transfected with vectors expressing p40 Met.

Real-time RT-PCR. Total RNA was extracted from the cells using the Nucleospin RNA/Protein Kit (Macherey-Nagel) according to the manufacturer's protocol. cDNA was reverse-transcribed from the total RNA with random hexamers using the High Capacity cDNA Reverse Transcriptase Kit (Applied Biosystems, Life Technologies, Green Island, NY, USA) according to the manufacturer's protocol. The mRNA expression of Bak and Bax were evaluated by real-time RT-PCR using Fast SYBR Green mix (Applied Biosystems) in an MX3005P instrument (Stratagene, La Jolla, CA, USA). The relative expression was calculated using the 2(- Delta Delta CT) method. The mRNA levels of each target gene were normalized to the levels of the housekeeping beta-2-microglobulin (B2M) gene and represented as fold induction. The primer sequences were as follows: Bak (Forward, 5'-AAATGGCTTCGGGGCAAGGC-3'; Reverse, 5'-CC TCCTCTGTGTCCTGGGCTAC-3'); Bax (Forward, 5'-TGGGCTGGACATTGGA CTTCCTC-3'; Reverse, 5'-ACTCCCGCCACAAAGATGGTCAC-3') and B2M (Forward, 5'-GCTGGCGGGCATTCCTGAAG-3'; Reverse, 5'-TGCTGGATGACGT GAGTAAACCTG-3').

Western blotting and immunoprecipitation. Western blotting was performed as previously described. ${ }^{11,30}$ For immunoprecipitation in MCF-10A, cells 
were cultured $24 \mathrm{~h}$ in serum-free medium. The next day, the cells were treated or not with staurosporin and lysed in PY buffer $(50 \mathrm{mM} \mathrm{NaCl}, 5 \mathrm{mM}$ EDTA, $1 \%$ Triton $\mathrm{X}-100,20 \mathrm{mM}$ Tris-HCL pH 7.4).

Immunofluorescence staining. After transfection, the cells were washed and fixed in $4 \%$ PFA at room temperature. The cells were washed and permeabilized with PBS containing $0.5 \%$ Triton $\mathrm{X}-100$ for $10 \mathrm{~min}$ at room temperature and blocked in $0.2 \%$ casein for $30 \mathrm{~min}$. Primary antibodies were incubated for $1 \mathrm{~h}$ at room temperature. Combinations of antibodies were used (mouse anti-C-terminal domain of mouse Met $(0.4 \mu \mathrm{g} / \mathrm{ml}$ ) with rabbit anti-cleaved caspase-3 (1:250); mouse anti-cytochrome-c $(5 \mu \mathrm{g} / \mathrm{ml})$ with rabbit anti-Flag $(1 \mu \mathrm{g} / \mathrm{ml})$ or rabbit anti-HA (1/5000)). The cells were washed with PBS and incubated for $60 \mathrm{~min}$ with a combination of Alexa Fluor-conjugated secondary antibodies (green-fluorescent Alexa Fluor 488-conjugated anti-mouse IgG $(\mathrm{H}+\mathrm{L})$ and red-fluorescent Alexa Fluor 594-conjugated anti-rabbit $\lg G(\mathrm{H}+\mathrm{L})$ diluted to $2 \mu \mathrm{g} / \mathrm{ml}$. The cells were washed with PBS and the nuclei counterstained with Hoechst 33258. Coverslips were mounted with Glycergel mounting medium (Dako, Carpenteria, CA, USA). For fluorescence microscopy, slides were observed in oil immersion with an Axion Imager Z1 (Carl Zeiss, Oberkochen, Germany), numerical aperture: ECL-PLAN NEOFLUAR $40 \times$ NA 1.3, with a monochrome Zeiss AxioCam MRm camera and the Axiovision acquisition software (Carl Zeiss). For confocal fluorescence microscopy, slides were observed in a LSM 710 Laser Scanning Microscope (Carl Zeiss), numerical aperture PLAN-APOCHROMAT $63 \times$ NA 1.4, with the ZEN acquisition software (Carl Zeiss).

Mitochondrial staining was performed $24 \mathrm{~h}$ after transfection. Cells were stained with $100 \mathrm{nM}$ MitoTracker (Invitrogen) for $30 \mathrm{~min}$ at $37^{\circ} \mathrm{C}$ and coverslips were immersed in methanol: acetone $(1: 1)$ at $-20^{\circ} \mathrm{C}$ for $10 \mathrm{~min}$. Cells were washed, $0.2 \%$ casein was added and incubation was carried out for $30 \mathrm{~min}$ to block nonspecific binding. Staining was performed as described above. Weighted colocalization coefficients were measured from the fluorescence confocal microscopy images with the ZEN acquisition software $\mathrm{M}=\frac{\sum_{i} C h 1 i, \text { colc }}{\sum_{i} C h 1 i \text {,total }}$

For annexin $\mathrm{V}$ staining, $1.10^{6} \mathrm{MDCK}$ cells were cultured on a $100-\mathrm{mm}$ plate and transfected or not by Lipofectamine reagents as described above. The next day, cells were harvested and stained according to the Tali Apoptosis Kit instructions (Invitrogen, Molecular Probes, Life Technologies). Briefly, Cells were incubated with Annexin V Alexa Fluor 488 and deposed in suspension in slide. Fluorescence was scanned with the Tali Image-based Cytometer (Invitrogen, Life Technologies).

In vitro kinase assays. Proteins were immunoprecipitated as described above. Immune complexes were washed four times with ice-cold lysis PY buffer and once with kinase buffer $\left(20 \mathrm{mM}\right.$ MOPS pH: $7.2,7.5 \mathrm{mM} \mathrm{MgCl}_{2}, 25 \mathrm{mM}$ glycerophosphate, $5 \mathrm{mM}$ EGTA, $1 \mathrm{mM} \mathrm{Na}_{3} \mathrm{VO}_{4}, 1 \mathrm{mM}$ DTT). Each immunoprecipitate was incubated for $30 \mathrm{~min}$ at $30^{\circ} \mathrm{C}$ with $20 \mu$ l kinase reaction buffer (kinase buffer supplemented with $50 \mu \mathrm{M}$ ATP and $10 \mu \mathrm{M}(10 \mu \mathrm{Ci})\left[\gamma-{ }^{33} \mathrm{P}\right]$ ATP (2000Ci/mmol) (Perkin Elmer, San Jose, CA, USA)). Kinase reactions were stopped by the addition of $10 \mu \mathrm{l}$ Laemmli sample buffer $(5 \times)$. The phosphorylated proteins were resolved using 12\% SDS-polyacrylamide gel electrophoresis and dried, and incorporation of $\left[\gamma^{33} \mathrm{P}\right]$ was visualized with autoradiography on hyperfilm-MP (Amersham, Arlington Heights, IL, USA).

Subcellular fractionation. MCF-10A cells were collected, washed in PBS, resuspended in buffer $(10 \mathrm{mM}$ Tris $\mathrm{pH} 7.6,250 \mathrm{mM}$ sucrose, $10 \mathrm{mM} \mathrm{KCl}$ $0.15 \mathrm{mMMgCl}_{2}$ ) and lysed using Dounce homogenization. The suspension was centrifuged at $850 \mathrm{~g}$ for $5 \mathrm{~min}$ at $4{ }^{\circ} \mathrm{C}$ to collect the nuclear fraction. The resulting supernatant was centrifuged at $20000 \mathrm{~g}$ for $15 \mathrm{~min}$ at $4{ }^{\circ} \mathrm{C}$ to pellet the mitochondria. The cytosolic fraction (supernatant) was then obtained by centrifugation at $100000 \mathrm{~g}$ for $1 \mathrm{~h}$ at $4^{\circ} \mathrm{C}$, and the cytosolic proteins were precipitated overnight with acetone at $-20^{\circ} \mathrm{C}$. Each fraction was resuspended in PY buffer and the same amount of protein was solubilized in Laemmli sample buffer.

Isolation of mouse liver mitochondria. Male C57BL/6 mice weighing $19-20 \mathrm{~g}$ and fasted overnight were injected intraperitoneally with $4 \mu \mathrm{g}$ anti-Fas antibody (Jo2antibody) per mouse or saline buffer. ${ }^{31}$ Mice were killed by cerebral dislocation and their livers were quickly removed and placed in ice-cold sucrose medium A (0.3 Mol/l sucrose, $5 \mathrm{mM}$ TES, pH7.2, $1 \mathrm{mM}$ EGTA, $1 \mathrm{mg} / \mathrm{ml} \mathrm{BSA}){ }^{32}$ The livers were minced and homogenized with a Potter-Elvehjem homogenizer with a loose-fitting pestle. Nuclei and cell debris were removed with centrifugation at $760 \mathrm{~g}$ for $10 \mathrm{~min}$ at $4{ }^{\circ} \mathrm{C}$. Then the supernatant was centrifuged at $8700 \mathrm{~g}$ for
$10 \mathrm{~min}$ at $4{ }^{\circ} \mathrm{C}$ to obtain the mitochondrial pellet and resuspended in $300 \mu \mathrm{l}$ medium A. To separate intact from broken mitochondria, the organelles were layered on Percoll gradients $(10 \mathrm{~min}$ at $8800 \mathrm{~g})$ consisting of a layer at $18 \%$, a layer at $30 \%$ and a layer at $60 \%$ Percoll $(\mathrm{w} / \mathrm{v})$ in medium $\mathrm{B}(0.3 \mathrm{Mol} / \mathrm{l}$ saccharose, $10 \mathrm{mM}$ TES, $0.2 \mathrm{mM}$ EGTA, $1 \mathrm{mg} / \mathrm{ml} \mathrm{BSA}, \mathrm{pH}$ 6.9). Then mitochondria-enriched fractions were collected from the $30 \% / 60 \%$ interface and washed $(10 \mathrm{~min}$ at $6800 \mathrm{~g}$ ) with medium A and the pellet was resuspended in $500 \mu \mathrm{l}$ medium A. Protein concentrations were determined using the BCA protein assay (ThermoFisher Scientific, Rockford, IL, USA).

Caspase activity. Adherent MDCK cells, detached with trypsin, and cells in suspension, collected after elimination of the medium by centrifugation, were lysed in PY buffer without protease inhibitor. Fifty microliter aliquots all containing the same amount of protein were transferred to a 96-well plate and $50 \mu$ lassay buffer (100 mM Hepes, 10\% Sucrose, $10 \mathrm{mM}$ DTT, $500 \mu \mathrm{M}$ EDTA) was added. After $30 \mathrm{~min}$ of incubation at $37^{\circ} \mathrm{C}$, the caspase substrate DEVD-AFC (Calbiochem) was added to each well and the fluorescence was monitored every $10 \mathrm{~min}$ for $3 \mathrm{~h}$ (excitation $=395 \mathrm{~nm}$, emission $=510 \mathrm{~nm}$ ) with a fluorimeter (BMG Labtech FLUOstar OPTIMA). The slopes of the activity curves were calculated and expressed with respect to the untreated control.

\section{Conflict of Interest}

The authors declare no conflict of interest.

Acknowledgements. We thank the Microscopy-Imaging-Cytometry Facility of the Lille Pasteur Campus (MICPal) and the Biolmaging Center Lille Nord-de-France for access to instruments and technical advice. This work was supported by the CNRS, the Institut Pasteur de Lille, and INSERM, and by grants from the the 'Ligue contre le Cancer, comité Nord', the 'Association pour la Recherche sur le Cancer', and the 'Agence Nationale de la Recherche', Young investigator Program. JL was supported by a grant from the French Research and Technology Ministry, GM by the 'Agence Nationale pour la Recherche'. We would like to thank for technical assistance and constructive discussions Cindy Gallerne, Christophe Lemaire (INSERM UMR S-769, Paris, France), and Patrick Dumont (CNRS, UMR 8161, IBL, Lille, France).

1. Mehlen $P$, Bredesen DE. Dependence receptors: from basic research to drug development. Sci Signal 2011; 4: $\mathrm{mr}$.

2. Tulasne D, Foveau B. The shadow of death on the MET tyrosine kinase receptor. Cell Death Differ 2008; 15: 427-434.

3. Trusolino L, Bertotti A, Comoglio PM. MET signalling: principles and functions in development, organ regeneration and cancer. Nat Rev Mol Cell Biol 2010; 11: 834-848.

4. Bladt F, Riethmacher D, Isenmann S, Aguzzi A, Birchmeier C. Essential role for the c-met receptor in the migration of myogenic precursor cells into the limb bud. Nature 1995; 376 : 768-771.

5. Schmidt C, Bladt F, Goedecke S, Brinkmann V, Zschiesche W, Sharpe M et al. Scatter factor/hepatocyte growth factor is essential for liver development. Nature 1995; 373: 699-702.

6. Uehara Y, Minowa O, Mori C, Shlota K, Kuno J, Noda T et al. Placental defect and embryonic lethality in mice lacking hepatocyte growth factor/scatter factor. Nature 1995; 373: 702-705.

7. Fan S, Wang JA, Yuan RQ, Rockwell S, Andres J, Zlatapolskiy A et al. Scatter factor protects epithelial and carcinoma cells against apoptosis induced by DNA-damaging agents. Oncogene 1998; 17: 131-141.

8. Yamamoto K, Morishita R, Hayashi S, Matsushita $\mathrm{H}$, Nakagami H, Moriguchi A et al. Contribution of Bcl-2, but not Bcl-xL and Bax, to antiapoptotic actions of hepatocyte growth factor in hypoxia-conditioned human endothelial cells. Hypertension 2001; 37: 1341-1348.

9. Liu Y. Hepatocyte growth factor promotes renal epithelial cell survival by dual mechanisms. Am J Physiol 1999; 277(4 Pt 2): F624-F633.

10. Tulasne D, Deheuninck J, Lourenco FC, Lamballe F, Ji Z, Leroy C et al. Proapoptotic function of the MET tyrosine kinase receptor through caspase cleavage. Mol Cell Biol 2004; 24: 10328-10339.

11. Foveau B, Leroy C, Ancot F, Deheuninck J, Ji Z, Fafeur V et al. Amplification of apoptosis through sequential caspase cleavage of the MET tyrosine kinase receptor. Cell Death Differ 2007; 14: 752-764.

12. Deheuninck J, Goormachtigh G, Foveau B, Ji Z, Leroy C, Ancot F et al. Phosphorylation of the MET receptor on juxtamembrane tyrosine residue 1001 inhibits its caspase-dependent cleavage. Cell Signal 2009; 21: 1455-1463.

13. Goldschneider D, Mehlen P. Dependence receptors: a new paradigm in cell signaling and cancer therapy. Oncogene 2010; 29: 1865-1882. 
14. Smolen GA, Sordella R, Muir B, Mohapatra G, Barmettler A, Archibald H et al. Amplification of MET may identify a subset of cancers with extreme sensitivity to the selective tyrosine kinase inhibitor PHA-665752. Proc Natl Acad Sci USA 2006; 103: 2316-2321.

15. Lutterbach B, Zeng Q, Davis LJ, Hatch H, Hang G, Kohl NE et al. Lung Cancer Cell Lines Harboring MET Gene Amplification Are Dependent on Met for Growth and Survival. Cancer Res 2007; 67: 2081-2088

16. Ogasawara J, Watanabe-Fukunaga R, Adachi M, Matsuzawa A, Kasugai T, Kitamura Y et al. Lethal effect of the anti-Fas antibody in mice. Nature 1993; 364: 806-809.

17. Hsu YT, Youle RJ. Nonionic detergents induce dimerization among members of the Bcl-2 family. J Biol Chem 1997; 272: 13829-13834.

18. Kurokawa M, Kornbluth S. Caspases and kinases in a death grip. Cell 2009; 138: 838-854.

19. Coleman ML, Sahai EA, Yeo M, Bosch M, Dewar A, Olson MF. Membrane blebbing during apoptosis results from caspase-mediated activation of ROCK I. Nature cell biology 2001; 3 : 339-345.

20. Sebbagh M, Renvoize C, Hamelin J, Riche N, Bertoglio J, Breard J. Caspase-3-mediated cleavage of ROCK I induces MLC phosphorylation and apoptotic membrane blebbing. Nat Cell Biol 2001; 3: 346-352.

21. Bachelder RE, Wendt MA, Fujita N, Tsuruo T, Mercurio AM. The cleavage of Akt/protein kinase $\mathrm{B}$ by death receptor signaling is an important event in detachment-induced apoptosis. J Biol Chem 2001; 276: 34702-34707.

22. Tulasne D, Paumelle R, Weidner KM, Vandenbunder B, Fafeur V. The multisubstrate docking site of the MET receptor is dispensable for MET-mediated RAS signaling and cell scattering. Mol Biol Cell 1999; 10: 551-565.

23. Willis SN, Chen L, Dewson G, Wei A, Naik E, Fletcher Jl et al. Proapoptotic Bak is sequestered by $\mathrm{Mcl}-1$ and $\mathrm{Bcl}-\mathrm{xL}$, but not $\mathrm{Bcl}-2$, until displaced by $\mathrm{BH} 3-$ only proteins. Genes \& development 2005; 19: 1294-1305.

24. Llambi F, Moldoveanu T, Tait SW, Bouchier-Hayes L, Temirov J, McCormick LL et al. A unified model of mammalian BCL-2 protein family interactions at the mitochondria. Mol Cell 2011; 44: 517-531.
25. Forcet $\mathrm{C}, \mathrm{Ye} X$, Granger L, Corset V, Shin H, Bredesen DE et al. The dependence receptor DCC (deleted in colorectal cancer) defines an alternative mechanism for caspase activation. Proc Natl Acad Sci USA 2001; 98: 3416-3421.

26. Liu J, Yao F, Wu R, Morgan M, Thorburn A, Finley RL Jr et al. Mediation of the DCC apoptotic signal by DIP13 alpha. J Biol Chem 2002; 277: 26281-26285.

27. Mille F, Thibert C, Fombonne J, Rama N, Guix C, Hayashi H et al. The Patched dependence receptor triggers apoptosis through a DRAL-caspase- 9 complex. Nat Cell Biol 2009; 11: 739-746.

28. Comoglio PM, Giordano S, Trusolino L. Drug development of MET inhibitors: targeting oncogene addiction and expedience. Nat Rev Drug Discov 2008; 7: 504-516.

29. Zeng Q, Tan YH, Hong W. A single plasmid vector (pSTAR) mediating efficient tetracyclineinduced gene expression. Anal Biochem 1998; 259: 187-194.

30. Foveau B, Ancot F, Leroy C, Petrelli A, Reiss K, Vingtdeux V et al. Downregulation of the Met receptor tyrosine kinase by presenilin-dependent regulated intramembrane proteolysis. Mol Biol Cell 2009; 20: 2494-2506.

31. Wang X, Lu Y, Cederbaum Al. Induction of cytochrome P450 2E1 increases hepatotoxicity caused by Fas agonistic Jo2 antibody in mice. Hepatology (Baltimore, Md) 2005; 42: 400-410.

32. Belzacq AS, Vieira HL, Verrier F, Vandecasteele G, Cohen I, Prevost MC et al. Bcl-2 and Bax modulate adenine nucleotide translocase activity. Cancer Res 2003; 63 . $541-546$.

Ca) (i) (2) Death and Disease is an open-access journal
published by Nature Publishing Group. This work is
licensed under a Creative Commons Attribution-NonCommercial-
ShareAlike 3.0 Unported License. To view a copy of this license, visit
http://creativecommons.org/licenses/by-nc-sa/3.0/

Supplementary Information accompanies this paper on Cell Death and Disease website (http://www.nature.com/cddis) 